\title{
The Effectiveness Of Application Of Cooperative Learning Strategies In Developing Innovation And Creativity Of Entrepreneurship Of Students Of Serambi Mekkah University
}

\author{
Cut Hamdiah ${ }^{1}$, Asnariza ${ }^{2}$, Sarboini ${ }^{3}$ and Musriadi ${ }^{4}$ \\ $\left\{\right.$ cut_hamdiah@yahoo.com ${ }^{1}$ and Asna_riza@yahoo.co.id $\left.{ }^{2}\right\}$ \\ ${ }^{1,2,3,4}$ Lecturer of the Faculty of Economics, Serambi Mekkah University, Banda Aceh, Indonesia
}

\begin{abstract}
College graduates still have a strong dependence on government and private institutions, college graduates are less able to see the existing market opportunities so they are not able to create and innovate to empower their potential and surrounding resources effectively and efficiently to meet the needs of life. The purpose of this study was to determine the achievement of the competency standards of students in Entrepreneurship courses with the implementation of cooperative learning and determine the effectiveness of the implementation of cooperative learning strategies in developing innovation and entrepreneurial creativity of students in Entrepreneurship courses. This research was a classroom action research. In this study, researchers were directly involved in the learning process; from identifying and formulating problems that occur, developing learning methods, carrying out each stage of the research to compiling reports. As for observation of the learning process in the classroom, the researchers were assisted by an observer. This study adopted the action research model from Kemmis (Kemmis, 1982). This type of research was classroom action research (CAR) which was carried out in two cycles, each cycle consisting of: (1) Action planning, (2) Implementation of actions and observations, and (3) Reflection. The successes and failures in the first cycle were identified, based on these shortcomings the researchers made improvements to learning in the second cycle. The results showed that student learning outcomes on entrepreneurial material by implementing cooperative learning strategies in developing innovation and entrepreneurial creativity of Serambi Mekkah University students experienced a significant increase. Lecturer activity in entrepreneurship learning by implementing cooperative learning strategies in developing innovation and entrepreneurial creativity Serambi Mekkah University students was categorized as good, this was indicated by the increased activity of lecturers with good scores. Student responded to cooperative learning in entrepreneurial materials can be categorized quite well. Whereas student activity in learning by applying cooperative learning was good.
\end{abstract}

Keywords: Cooperative Learning Strategy, Developing Student Innovation and entrepreneurial Creativity 


\section{Introduction}

The challenge of higher education today is to produce graduates who are competent not only in science but also in practicality. Students with scholarships can be shown with a high achievement index, but creating an independent human being is not easy. A college graduate is expected to be directly involved in the community to apply his knowledge. In reality, college graduates still cannot independently work. The facts show that in 2004 the college graduates contributed around 2000 people or $17 \%$ of the total national unemployment [1], and in the following year the number did not decline. The problem of educated unemployment should be a shared concern and thought among educators who are contributors to the quality of higher education graduates. The problem of educated unemployment gives a warning to universities, that the responsibility of implementing higher education does not stop after students are graduated but up to the graduates are independent. This means that the curriculum in higher education must prepare graduates to be independent [1]. One solution is to enrich entrepreneurship aspects in college curricula or provide more intensive Entrepreneurship lecture practices. By enriching the entrepreneurial aspects both in theory and practice in lectures, students are expected to have enough provision to think creatively and innovatively in accordance with the soul and entrepreneurial spirit. After graduating from college, students not only can wait to get a job, but can create jobs for others.

Based on the fact that college graduates today still have a strong dependence on government and private institutions, university graduates are less able to see the existing market opportunities so they are unable to create and innovate to empower their potential and surrounding resources effectively and efficiently. In order to fulfil life's needs. The attitude of being less responsive to the changes in the surrounding environment is partly due to the curriculum content in universities in general not integrating entrepreneurship spirit properly. The integration of the culture of entrepreneurship into courses is considered important and rational enough to prepare college graduates who are professional, creative, responsible, and independent (Kokom Komariah, 2006: 1). Creativity and innovation that are strongly owned by students are expected that students are able to sustain the growing culture of entrepreneurship among universities. At college, creativity is often excluded either consciously or not. In the teaching and learning process there is direct interaction and communication between lecturers and students. Lecturers indirectly limit the transfer of knowledge to students and this is often not realized by the lecturer. For example, students make something that is not in accordance with the taste of the lecturer will get a bad score. Slowly this will erode the creativity side of students to innovate and develop their creativity. A creative person always tries to get ideas or new things almost every time. If this is hampered, it is likely that creativity cannot develop or even become blunt.

College graduates who do not have selling value, high entrepreneurship and creativity will be increasingly difficult to compete. Higher education institutions as a collection of professional academic communities have considerable challenges to provide solutions to these problem solving by integrating entrepreneurship insight with teaching.

When reviewing the Entrepreneurship lecture practices in the college curriculum, what is conveyed in lectures is limited to theory only, has not provided entrepreneurship practices in real terms, so that the ability of students has not been optimal. Competency standards in Entrepreneurship courses require students to be able to develop a business plan or a business establishment plan. Through the preparation of this business plan students will practice developing their ability to plan the establishment of a particular business / business, starting from the statement of the business theme, business vision and mission, to the business 
strategy, human resource management, finance, production and marketing. Entrepreneurship learning output targets should be clearer, and require task-oriented applications that lead to the implementation stage of entrepreneurship so that students are ready to enter entrepreneurship in the real world. Task-oriented will encourage students to be responsible for lecture assignments and try to complete the task. The implementation of task-oriented in Entrepreneurship lectures is not only limited to the preparation of business plans, but is continued with the implementation of a business plan so that the competency standards that students can achieve are even better. Task-oriented is the core of implementing cooperative learning strategies. In cooperative learning, students in small groups will work with their group teams to solve problems.

Based on the title above, the objectives of this research are:

1. Knowing the achievement of student competency standards in Entrepreneurship courses with the implementation of cooperative learning.

2. Knowing the effectiveness of implementing cooperative learning strategies in developing innovation and entrepreneurial creativity of students in entrepreneurship courses.

\section{Research Method}

\subsection{Creativity and Innovation}

Creativity is defined as the use of imagination and ingenuity to achieve something or to get unique solutions in overcoming problems [2]. Creative is not innate from birth but something that can be created and trained by giving stimulus or inducement to the brain. Games, or making pictures can stimulate the brain to think creatively. By practicing creative thinking, the inspiration to do, make, and create something is wide open so that it can produce something innovative.Innovation is the process of developing new ideas or incorporating new ideas in practical activities so that there is a conversion of new ideas in useful applications. Applications of new ideas occur in the form of an innovation process that produces ways or methods that are better in doing something will produce something innovative.

The potential for creativity is in everyone. Entrepreneurship is closely related to creativity and innovation because: 1) the core of entrepreneurship is the ability to create something new and different through creative thinking and acting innovatively to create opportunities. Therefore entrepreneurship is closely related to creativity (Suryana, 2003: 2); 2) according to Milgram [3] intelligence or IQ simply cannot predict creativity in real life; 3) Furthermore Rowe (2004) says that general intelligence supports several types of creativity, but it is not necessarily able to support or guarantee all types of creativity. Creative intelligence is open, innovative, inventive, unlimited, brave, spontaneous, fantastic, imaginative, unpredictable, revolutionary and free-spirited, while general intelligence has the characteristics of focus, discipline, logical, limited, simple, realistic, practical, serious, stable and conservative [4].

Definition of creativity [3] includes:

a. Creativity is the ability to create new combinations based on existing data, information or elements.

b. Creativity (creative thinking or divergent thinking) is the ability to share available data or information, find many possible answers to a problem whose emphasis is on the usefulness and diversity of answers.

c. Operationally creativity can be formulated as an ability that reflects fluency, flexibility, original thinking, and ability to elaborate (develop, enrich, detail) an idea. 
According to Cropley [3] creative ability is the ability to create ideas, recognize alternative possibilities, see unexpected combinations and have the courage to try something unusual. Or in other words, student creativity is the ability to provide new ideas that can be applied in problem solving.

Motivation is the process of translating ideas and transforming them into useful products, services or methods [5]. There are several things that are driving factors for innovation, namely:

1. structural variables, including organizational structure, resources, and communication that occur within the organization.

2. cultural variables, including acceptance of ambiguity, tolerance of impractical matters, low external control, tolerance for risk, tolerance for conflict, focus on results, and an open system.

3. human resources variable, including high commitment to training and development, level of job security, and creative people resources.

According to [3]. teaching and learning activities that foster children's creative ideas can be carried out through the creation of a classroom environment that stimulates creative learning and asks questions. The creation of a classroom environment that stimulates creative learning can be done through the following things.

1. Provide open questions that generate interest and stimulate student curiosity. Lecturer questions are submitted together with demonstrations at the beginning of learning (preliminary phase).

2. Physical arrangements, for example seating arrangements according to student activities. Lecturers group students into eight groups. Students sit face-to-face in their respective groups during the practicum (excavation phase) and students sit focused on facing forward when the introductory phase, explanation, application of concepts, and evaluation.

3. Busy activities in an exciting class, such as group practicum activities and direct experience with concrete objects.

\subsection{Entrepreurship}

In an estimological sense wira means primary, manly, noble and noble, whereas swa means personal or self-strength and sta means standing, striving to live alone wisely, noble and independent. Thus, entrepreneurs can be interpreted as the characteristics of courage and exemplary in taking risks that stem from their own strengths and abilities. From the above definition, it can be obtained the description that entrepreneurship is an effort carried out by people who dare to take risks and dare to stand alone for the field of employment or living for their own lives and other people who can be accommodated. Entrepreneurship is the spirit, behaviour and ability to give a positive response to the opportunity to gain benefits for themselves and or better service, and create and provide products that are more useful and implement efficient work methods, through the courage to take risks, creativity and innovation and management ability. The above definition includes the essence of entrepreneurship, namely a positive response to opportunities to gain benefits for themselves and or better service to customers and society, ethical and productive ways to achieve goals and mental attitudes to realize these positive responses. Enthusiasm, behaviour and entrepreneurial abilities certainly vary from one another and on that basis entrepreneurship is grouped into three levels: initial entrepreneurship, tough entrepreneurship, superior entrepreneurship. Entrepreneurs whose behaviour and abilities are more prominent in mobilizing resources and funds, and transforming them into outputs and marketing them efficiently are commonly 
called Administrative Entrepreneurs. On the contrary, entrepreneurship is the behaviour and ability to stand out in creativity, innovation and anticipating and dealing with risks commonly called Innovative Entrepreneurs.

\subsection{Cooperative Learning Strategy}

How each student interacts with one another is an important aspect of a classroom instruction. There are several ways students can interact with other students. They can compete to find out who is the best, or they can work individually to achieve the goals of the lecture without paying attention to and collaborating with other students, or they work together to establish the same interests as learning from each other. The last thing is the core of cooperative learning methods. Cooperative learning involves collaborating between students by learning to fight together, completing a work together, supporting each other, celebrating mutual success, by ignoring cultural and gender backgrounds [6].

Several things that condition the occurrence of cooperative learning are:

1. A clear positive interdependence.

2. Face-to-face interaction (promotive interaction).

3. The existence of accountability and individual responsibility to achieve common goals in a positive relationship.

4. Use of interpersonal skills in small groups (phycological, adjustment, social competence).

5. There is a process of improving future effectiveness (effort to achieve).

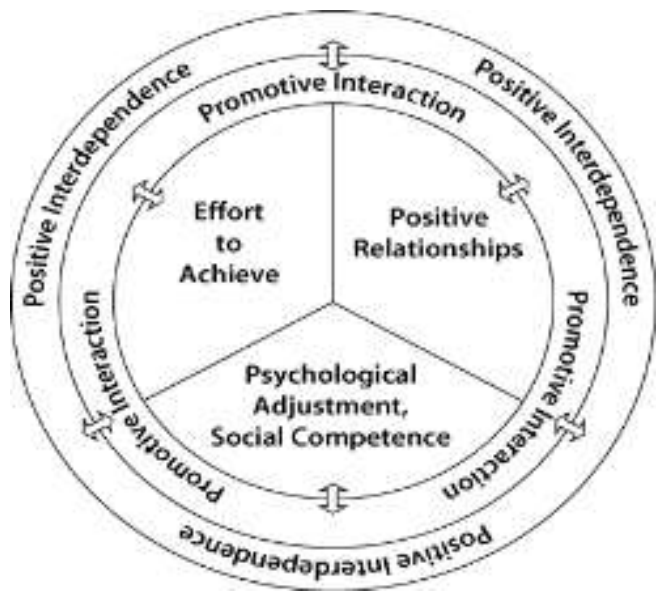

Fig 1. of Cooperative Learning Elements

The main requirement of effective cooperative learning is when every student in his group believes they swim together or they sink together. In the classroom situation, students have two (2) responsibilities, namely learning teaching materials and ensuring that each group member learns the teaching material. Positive interdependence occurs when group members feel that group success will not be achieved if other group members do not cooperate. Therefore, every student in the group must coordinate with each other to complete the lecture assignments. With positive interdependence, the contribution of each student is needed, which results in the absence of free riders in the group. In addition, every student in the group will have a unique contribution depends on their responsibilities and resources to achieve group goals. 
Positive Interdependence influences face to face interactions. This interaction is characterized by cooperation between members in groups effectively and efficiently to help each other, exchange information and resources, provide feedback as a means of improving members of other groups, influence each other to work together to achieve goals, build trust with each other and prioritize higher quality decision making. With this interaction the motivation of the group will wake up and avoid conflict and stress in the group.

The third element of cooperative learning is individual accountability, which occurs when an individual's performance is assessed, then the results are given to the group and the individual is responsible for achieving group success. It is important when the group knows which members need help and support to complete the task. The purpose of cooperative learning is to make each group member stronger in their rights. To ensure that each group member contributes fairly, the lecturer must provide an assessment for each group member, provide feedback, help the group to avoid conflict / stress, and ensure that each individual is responsible for the final result of group work.

Several ways that can be done to get accountability and responsibility of individuals optimally are:

1. forming a small group so that it can be clearly known which group members have good accountability and responsibility,

2. providing an assessment for each group member,

3. asking the performance of a group member to other group members,

4. giving tutorials / explanations to other group members when someone has understood something (simultaneous explaining).

The fourth element of cooperative learning is the use of appropriate interpersonal skills in groups. To coordinate efforts to reach group goals, each member must 1) know each other, 2) communicate with each other accurately and unambiguously, 3) accept and support each other and 4) solve problems constructively. Interpersonal skills are not innate. This ability is not a present, it requires social ability to collaborate with high quality and motivated to be more productive. The better the social abilities of group members are, the higher the chances of achieving group goals.Effective group performance is influenced by how well the group functions. Group processes are achieved over a long period of time, and the process of achieving goals involves all elements of the organization to fight together. The process of improving this group means: 1) describing whether the behaviour of group members is helping each other or not, 2) determining decisions about whether a decision is continued or changed. The purpose of this group improvement process is to clarify and increase the effectiveness of group members in contributing and collaborating efforts to achieve group goals. One of the important aspects of the group improvement process is a sense of mutual success, being appreciated and respected by each other so as to build learning commitment, enthusiasm to work in groups, and confidence to cooperate cooperatively.

Cooperative learning has been widely used in classroom learning. One of the basic principles of cooperative learning is the principle of heterogeneous grouping. In cooperative learning, diversity will more effectively produce richer ideas and a better learning experience. In addition, important abilities such as critical thinking, creative problem solving and knowledge creation can be easily achieved through group activities. Some opinions also state that cooperative learning occurs when group goal learning is very important, the task assigned to the group is relatively complex, it requires analysis of problem solving, creativity and high group performance and group dynamics strategies. The group's goal is the achievement of the task given, so that all group members concentrate on solving the problem. 
Cooperative learning will be very useful in small groups, because in small groups each member is allowed to make optimal contributions to achieve group goals / tasks. In addition, each member will develop their interpersonal skills, engage with group conflict, but with clarity of purpose and shared commitment, an increase in learning understanding will be achieved. Each group member is not only responsible for himself, but also must help other members to understand learning so that the group's goals / tasks are achieved (http://edtech.kennesaw. edu/intech/cooperativelearning.htm).

\section{Result and Discussion}

\subsection{Research Approach}

This research was a classroom action research. In this study, researchers were directly involved in the learning process; from identifying and formulating problems that occur, developing learning methods, carrying out each stage of the research to compiling reports. As for observation of the learning process in the classroom, the researcher was assisted by an observer.This study adopted the action research model from Kemmis (Kemmis, 1982). This type of research was classroom action research (CAR) which was carried out in two cycles, each cycle consisting of: (1) Action planning, (2) Implementation of actions and observations, and (3) Reflection. The successes and failures in the first cycle were identified, based on these shortcomings the researchers made improvements to learning in the second cycle.

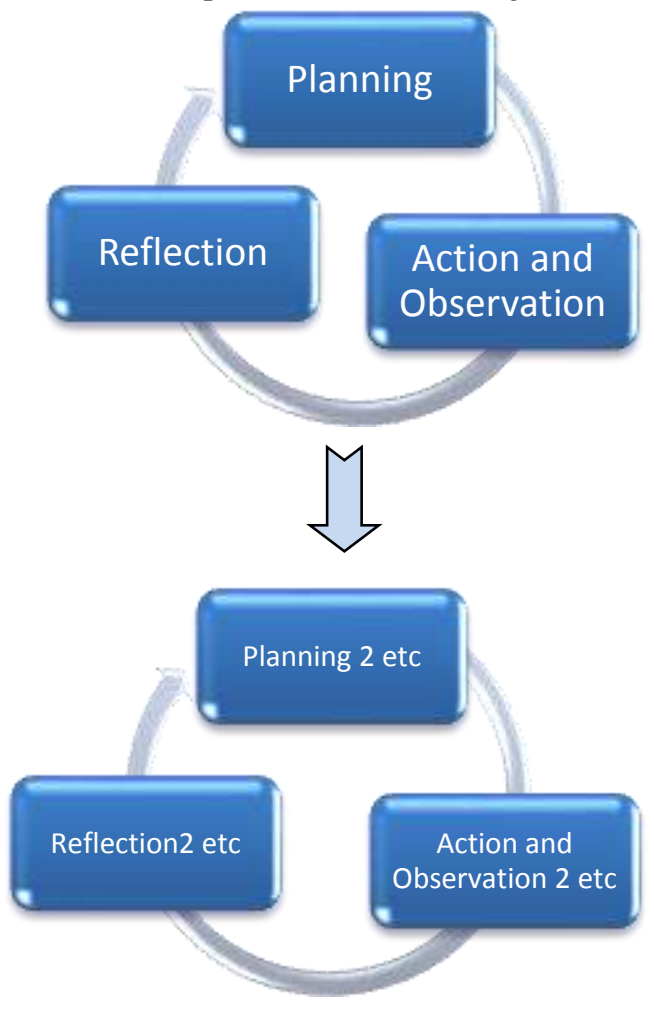




\subsubsection{Place and time of research}

The research was carried out in the Accounting and Management Study Program of the Faculty of Economics, Serambi Mekkah University.

\subsubsection{Research Subjects and Objects}

The subjects of this class action research activity were students of the Accounting and Management Study Program of the Faculty of Economics, Serambi Mekkah University who had taken entrepreneurship courses. The object of research was the method of entrepreneurship culture based on creativity and innovation in students.

\subsection{Research procedure}

1. Action Planning Phase

At this stage, researchers used the results of observations from the implementation of Entrepreneurship lectures in the previous semester to find out the problems that occurred during the lecture.

After the problem was successfully formulated, the researcher then determines the learning strategy / model that is deemed appropriate to solve the problem. Cooperative Learning model was task-oriented which must be achieved by students in the group chosen to solve problems.

The next step was to plan the learning activities that was carried out during the lecture. This activity was formulated in accordance with the Cooperative Learning model. The steps are as follows:

a. Arranging lecture design

b. Compiling lecture units

c. Arranging tasks / assignments (individuals and groups)

d. Compiling student groups

e. Compiling a questionnaire

f. Compiling observation sheets

g. Preparing interview guidelines

2. Action Planning Phase

At this stage, researchers used the results of observations from the implementation of Entrepreneurship lectures in the previous semester to find out the problems that occurred during the lecture.

After the problem was successfully formulated, the researcher then determines the learning strategy / model that is deemed appropriate to solve the problem. Cooperative Learning model was task-oriented which must be achieved by students in the group chosen to solve problems.

The next step was to plan the learning activities that was carried out during the lecture. This activity was formulated in accordance with the Cooperative Learning model. The steps are as follows:

a. Arranging lecture design

b. Compiling lecture units

c. Arranging tasks / assignments (individuals and groups)

d. Compiling student groups

e. Compiling a questionnaire

f. Compiling observation sheets

g. Preparing interview guidelines 
3. Phase of Action and Observation

The action was carried out in accordance with the learning scenario, with the following learning settings:

a. Modular learning.

b. Conducting field visits.

c. Arranging the tasks that were ordered in a module in the form of a business plan.

d. Presenting business plans.

e. Implementing of business design, which was carried out through integration with other practice courses.

f. Monitoring, reflection and evaluation before, during and after the activities are carried out, until the target set can be achieved.

At this stage the researcher also observes the process and results of teaching through: (1) noting students' difficulties in carrying out the learning process; (2) orientation and field visits, (3) discussions / brainstorming, (4) idea restructuring, (5) problem solving assignments, (6) construction of ideas in the form of activity plans and (7) evaluation of plans (8) applying the plan, (9) giving lecture questionnaires to students and asking them to give feedback (written feedback).

Personnel involved in the action were divided according to the implementation schedule agreed upon in the design forum. Each cycle displayed a form of activity that led to the product of the other courses of practice that have been determined. The role of researchers as observers as well as evaluating the progress achieved by each group. For students of accounting study programs can do entrepreneurship by integrating with courses. Whereas for students from management study programs can do entrepreneurship by integrating with courses. As long as students do entrepreneurship, the lecturer acted as an observer who assessed business creativity, management of products produced, marketing done and service given to consumers. When doing the activity the lecturer at the same time doing reflection.

Observations were carried out with the implementation of actions. The tools used for observation were student observation sheets which consisted of the ideal pattern of entrepreneurial behaviour, creativity shown, technical abilities which included aspects of production, service aspects, marketing aspects, and managerial abilities.

Observations were carried out by lecturers as participatory researchers and other researchers as observers from outside the classroom to keep the learning situation going naturally. Objects observed included patterns of behaviour that reflect students' entrepreneurial abilities and the application of creativity. Specific events that were not designed beforehand during the learning process were also observed using anecdotal notes.

Observations were carried out with the implementation of actions. The tool used to observe consisted of observation sheets of student behaviour. Observation of student behaviour was carried out by researchers and observers from outside to keep the learning situation going naturally.In particular, observation instruments were used to evaluate the performance achieved by students in aspects of production skills, management skills, creativity and marketing ability, and indicators of success in marketing activities. Observations were made on individual and group activities. In addition to use observation sheets, researchers used several data collection instruments, namely interview guidelines, questionnaires, tests and portfolio documents. Interviews were conducted with several random students.

Improving the quality of learning was observed based on specific notes observed from lecturer learning activities, student learning behaviour, achievement of student competency standards, and learning climate. 
4. Data Analysis, Evaluation and Reflection

The data obtained in this study were qualitative and quantitative data. Quantitative data were analysed through tables, and qualitative data were analysed using procedures: (1) data reduction to simplify data through selection, classification and simplification of raw data into information that has meaning, (2) Narrative data explanation about the process and results of actions , (3) Conclusion in the form of short sentences or the essence of the results of the study. Based on observations, the lecturer then reflected. Reflection on the process and results were the basis for subsequent planning.

\subsection{Student Learning Outcomes}

Data obtained from test scores in the first cycle, showed that student learning outcomes were still not achieving the target) from 20 students, there were 9 students (36\%) got very good grades, 6 students (24\%) students who got good grades, 10 people (40\%) students who get enough grades. The student highest scores obtained in the first cycle was 90 while the lowest score was 56. This was due to several constraints found in cycle I including:

1. There are some students who were less antuism in following the learning process, because students had not adapted to the Cooperative learning model in developing innovation and entrepreneurial creativity and students were overwhelmed in solving the given questions according to the specified time so as to influence student learning outcomes in cycle I.

2. students still lack enthusiasm when answering questions and solving problems, less brave in submitting opinions or comments on group presentations, so that students were less aware of the material being taught.

3. All students did not listen to the teacher explain the lesson and did not take the test given properly, so that the test results in the first cycle had not reached the expected target.

Based on the results of reflection in the first cycle, it is necessary to improve the activities of lecturers and students in cycle II, namely:

1. For lecturers: providing motivation, guiding students to find answers and resolving them, telling students to discuss learning material reflection (cooperation, communication, asking) clarifying the material more deeply so that students are able to understand the material well in cycle II and obtain the expected learning outcomes.

2. For students, must be enthusiastic in taking lessons, listening carefully to what the lecture explains, dare to express opinions and take the test well. After being given a test in cycle II, there was an increase in student learning outcomes, from 20 students in the university class, there were 14 students $(76 \%)$ who got very good score, 3 people $(12 \%)$ students who got good score, 3 people (12\%) students who get enough score, while students who get less score was $(0 \%)$.

This showed that student learning outcomes towards the implementation of cooperative learning strategies in developing the entrepreneurial innovation and creativity of the students of the Serambi Mekkah University still have not reached the maximum value, so researchers need to provide action in the next cycle (cycle III). Based on the results of reflection in the second cycle all the activities of lecturers and students during the learning process have been improved 


\section{Conclusion}

Based on the results of data analysis and discussion obtained in the study, it can be concluded that:

1. Student learning outcomes on entrepreneurial material by applying cooperative learning strategies in developing innovation and entrepreneurial creativity of university students in Serambi Mekkah university has a significant increase.

2. The activity of lecturers in entrepreneurial learning by implementing cooperative learning strategies in developing innovation and entrepreneurial creativity of university students in Serambi Mekkah university is categorized as good, this is indicated by the increasing activity of lecturers with good scores.

3. The response of students to cooperative learning on entrepreneurial material can be categorized quite well.

4. While student activity in learning by applying cooperative learning is good.

\section{References}

[1] A. A. Setyawan, "Educated Unemployment vs. College Quality," FE UMS Econ. Bus. Artic., 2005.

[2] S. Susanto, Implementation of Entrepreneurship Insights in Research in Higher Education. Yogyakarta: IKIP Yogyakarta, 1999.

[3] U. Munandar, Development of Creativity in Gifted Children. Jakarta: Rineka Cipta, 1995.

[4] N. Susiana, Chemistry Learning Program to Grow Entrepreneurial Attitudes of High School Students. Jakarta: Pelita Harapan University, 2005.

[5] S. Robbins and M. Coulter, Management. New Jersey: Prentice Hall, 1999.

[6] R. T. Johnson and D. W. Johnson, Improving the Quality of Teaching and Learning Process through Cooperative Learning. Baltimore: Brookes Press, 2004. 